\title{
A Real-Time Combustion Instability Simulation with Comprehensive Thermo-Acoustic Dynamic Model
}

\author{
Jaeyoung Han, Jiwoong Jeong, Kyungin Cho and Sangseok Yu * \\ Department of Mechanical Engineering, Chungnam National University, 99 Daehak-ro, Yuseong-gu, \\ Daejeon 34134, Korea; hjyt11@gmail.com (J.H.); winj2u@naver.com (J.J.); ruddls070@naver.com (K.C.) \\ * Correspondence: sangseok@cnu.ac.kr; Tel.: +82-42-821-5646; Fax: +82-42-822-5642
}

Received: 6 March 2018; Accepted: 4 April 2018; Published: 10 April 2018

\begin{abstract}
The thermo-acoustic instability in the combustion process of a gas turbine is caused by the interaction of the heat release mechanism and the pressure perturbation. These acoustic vibrations cause fatigue failure of the combustor and decrease the combustion efficiency. This study aims to develop a segmented dynamic thermo-acoustic model to understand combustion instability of a gas turbine. Then, the combustion instability was designed using the acoustic heat release model, and the designed instability model was segmented using the finite difference method, to evaluate the characteristics of flame propagation at each node. The combustion instability model was validated using experimental data to verify the instability amplitude. Also, the optimal node number was determined using the adiabatic flame temperature response. 10 nodes were selected in this study. A sensitivity analysis showed the predicted instability amplitude decreased when the nodes increased until node 4 , due to heat generation. However, above 4 nodes the amplitude decreased, since the combustion outlet was directly connected to the ambient. As a result, the segmented combustion instability model was able to evaluate the flame propagation characteristics more accurately and found the largest area of instability was near the flame area.
\end{abstract}

Keywords: combustor; segment; turbulent premixed flame; combustion instability; flame propagation; finite difference method

\section{Introduction}

\subsection{Research Motivation}

The depletion of energy resources and growth of environmental pollution are critical concerns at the turn of the 21st century [1-3]. As emission regulations become more stringent in efforts to suppress pollution, many researchers are working on developing a new type of power plant which produces significantly lower emissions: an advanced gas turbine. A stationary gas turbine is a power plant that converts the chemical energy of fuel to mechanical work using combustion to turn a turbine $[4,5]$. This combustor, however, emits $\mathrm{CO}, \mathrm{CO}_{2}, \mathrm{NO}_{\mathrm{x}}$, and other atmospheric pollutants [6-8]. For this reason, combustor type stationary gas turbines typically employ low $\mathrm{NO}_{\mathrm{x}}$ technologies to reduce emissions because low $\mathrm{NO}_{\mathrm{x}}$ emission can protect generation of smog upon exposure to sunlight and acid rain [9]. However, such systems reduce the stability of combustion inside the burner.

In general, the typical combustor in a gas turbine employs a turbulent lean premixed combustion method, as an alternative to the diffusion flame method $[10,11]$. The diffusion flame method generates sharply higher levels of $\mathrm{NO}_{x}$ because of the local high temperature, while the turbulent lean premixed method is more economical as well as having the advantage of low $\mathrm{NO}_{\mathrm{x}}$ production [12]. However, the lean premixed combustion technology has critical issues, including sensitivity to operating characteristics, a small limit of inflammability, a complex combustor structure, and high-level 
technology [13]. Thermo-acoustic problems may also occur, largely due to the geometric shape of the combustor structure and chemical reactions during combustion, leading to combustion instability [14]. Among other reasons, the combustion instability occurs in the combustor chamber due to acoustic oscillations in the chamber, which are produced by interactions between the heating mechanism and pressure oscillations $[15,16]$.

Combustion instability is characterized by heat release oscillations, inlet flow perturbations, and flame location, coupled with a continuous increase in pressure oscillation amplitude, and acoustic oscillations in the combustor chamber [17]. These instabilities are a major obstacle to achieving low- $\mathrm{NO}_{\mathrm{x}}$ emissions, and they may lead to serious failure of the entire gas turbine components [18]. Fatigue failure may occur in the combustor due to acoustic oscillations. Thermal fatigue fracture, low combustion efficiency, and increasing emissions may be produced by the increasing rate of heat transfer to the combustor wall [19].

For these reasons, an evaluation of combustion instability should be conducted to ensure the durability and performance of the gas turbine. Unfortunately, however, it is very difficult to evaluate combustion instability using an experimental approach, due to the scale of the test bench, the high cost, and the long test period. As a result, a combustion model of the gas turbine that can evaluate the combustion instability in the combustor is needed. Since the amplitude of the combustion instabilities in the combustor chamber can vary in different regions, a segmented approach is needed to analyze the combustion instability in the combustor chamber. The analysis is focused on the premixed flame segment and is based on the linear equation for a perturbed flamefront. Both acoustical stabilization of the hydrodynamic flame instability and excitation of the parametric instability by sound waves are considered, and the limitation for stable/unstable regimes as a function of flame parameters and acoustic frequency/intensity is determined.

\subsection{Literature Survey of the Combustion Instability}

Combustion instability in the gas turbine is caused by interactions between the heating mechanism and pressure oscillations in the chamber. It is challenging to model combustion instability, because it is difficult to design a combustion instability model with sufficiently high fidelity. Several previous studies have worked on modeling combustion instability in gas turbines. Hathout et al. analyzed combustion stability using periodic fuel injection to determine the stable operating envelop. A heat release model with fluctuations was related to the flame surface area, which was coupled with velocity fluctuations and local flame speed. Conservation of momentum was used to express the correlation between the velocity and pressure. In this way they were able to derive a second-order ordinary differential equation for the pressure oscillation [20].

Yuan et al. investigated a self-excited high frequency combustion instability in a rocket combustor. The combustion instability was represented by point measurements, Fast Fourier Transform, and instantaneous flowfield contours. A proposed heat flux profile agreed with the experimental data. They also demonstrated acoustic oscillation modes and frequencies using proposed simulations which almost agreed with classic acoustic analysis [21]. Yuan et al. also simulated a large eddy in a combustion instability in a tri-propellant air heater to predict self-excited transverse oscillations. Mode shapes, Rayleigh index, pressure time histories, and the unsteady response of the injector were found to affect the overall behavior of combustion instability. For this reason, correlations in the overall behavior of the combustion instability were studied in detail. In addition, a proposed new process that is to predict the acoustic oscillation modes and corresponding frequencies by current simulations was identified in the simulation and compared to previous investigations [21].

$\mathrm{Li}$ et al. presented a thermo-acoustic analysis of long flames in combustors using a coupled low-order method. They also expressed the propagation characteristics in the long flame region and validated their analysis with experimental data which measured limit cycle characteristics. That study, however, did not analyze heat-acoustic propagation in the entire combustor and was unable to show the change in operating conditions over time [22]. 
Keller et al. investigated thermo-acoustic oscillation in gas turbine combustors. Premixed combustion is widely used in gas turbines; however, it is difficult to stabilize premixed flames, and this is a critical issue in modern combustion technology. For this reason, Keller investigated the influences of a variety of self-excited oscillations that are forced by aerodynamic instabilities. Eventually, they reported that the periodic extinction and vortex rollup mechanisms were dependent on each other [23].

Lieuwen et al. described an experimental approach of limit cycle oscillations in a gas turbine to understand the effects of characteristics on the limit cycle oscillations and the nonlinear processes. A statistical analysis and limit cycle pressure oscillations were first investigated, and then the role of noise and system oscillations were described. Finally, the importance of the combustor inlet velocity, which determines the amplitude of oscillations, was discussed [24]. Schuermans et al. proposed transfer functions in a thermo-acoustic modeling approach for a gas turbine. The functions of the frame and burner were derived from the full engine pressure data. The acoustics were compared using acoustic-optical methods. They also implemented the transfer functions in a nonlinear, three-dimensional model of an annular combustion chamber [25].

Bellucci et al. simulated acoustic pulsations to present a TA3 that is a tool for combustion analysis thermos-acoustic network thermo-acoustic network. The primary multi-burner model was comprised of a hood and combustor. A three-dimensional modal analysis was used to obtain the MIMO that is a system with multi input and multi output transfer function. Since the flame model is based on the time-lag, an s-domain approach was converted to a state space time domain [26].

The estimated flame segments of triple flames were analyzed by Akkerman et al. [27]. The combustion instability of an acoustic field was based on the linear equation for an oscillating flame front. They focused on the premixed flame segment approach of triple flames. O'Connor et al. introduced combustion instabilities characterized by heat release rate oscillations and high acoustics in a combustor chamber. They also discussed the fundamentals of thermo-acoustic feedback cycles, combustion control strategies, future design technology, and the research paradigm for combustion instabilities [28].

\subsection{Objective and Outline of This Paper}

The lumped combustor model is a system that components can be treated as independent zero-dimensional block. For this reason, the combustion instability process cannot be analyzed in detail by region. Thus, a segmented combustion instability model is needed. Also, the authors added a brief description of the umped system to the text and modified analytical approach model to analytical model.

Nevertheless, only lumped combustor analytical models exist in the previous papers on gas turbine combustors, and this lumped approach cannot assess variations in temperature and density in the combustor $x$-axial direction. The combustion instability models also used lumped analytical approach models, even though the flame propagates along the x-axial in the combustor. To evaluate the combustion instability along the horizontal direction, a segment analysis of both the combustor and combustion instability is needed.

The previous model by Li et al. [22] is a useful concept but it is not adequate to assess a segmented instability because it only considers one combustor volume and long flames. To develop a segmented combustor and combustion instability model, a node analysis was used, with further experimental data on the heat release, the frequency spectra of velocity, and pressure perturbations. At each node, the remaining mixture reacts to the next node and responds. So, the temperature and density of the species will move along the nodes. The node method can be used to determine the amplification location of the combustion instability and to derive a method for controlling the safety zone.

The focus of this study was to evaluate the combustor and combustion instability in the combustor under different operating conditions using an analytical approach. Then, the designed lumped combustor model was distributed into ten segments to evaluate the combustor dynamics while the combustor model was operating. Also, since the combustion instability is dependent on the combustor 
temperature and the density of chemical species, the combustion instability should be distributed to nodes. If one model is designed as a lumped model, it is difficult to understand the characteristics at each position. However, the node method can analyze the combustion characteristics according to the position of the combustor.

In this design, the heat release, pressure perturbations, and thermo-acoustic combustion instability along the horizontal direction in the combustor were distributed to eight nodes.

This paper is structured in the following way. First, the combustor model is briefly introduced, and the segment combustor model is explained in Section 2. The segment combustion instability modeling approach is explained in Section 3. Section 3 also provides the model validation using experimental data. Finally, results and discussion are provided in Section 4. The conclusions are presented in Section 5.

\section{Quasi Steady State Combustor Modela}

\subsection{Geometrical Configuration}

Simulations were carried out using an accurate configuration and a test bench to validate the combustion model. Most previous combustor models have used the Well Stirred Reactor (WSR) reaction model, which focuses on the transient responses of the flame. The WSR model, however, cannot express a detailed combustion process in a combustor. The WSR model assumes that mixing time is faster than chemical reaction time. Therefore, the physical properties within control volume are uniform, and the characteristics of the flame and the size of instability heat release can be understood. For this reason, in this study, a segmented combustor model was employed to evaluate the detailed combustion process, to ensure the accuracy of the model for each region in the combustor. Another reason for adopting this approach was to apply the thermo-acoustic combustion instability in the combustor model.

Figure 1 shows the schematic of the overall combustor model used in this study. The segment is divided into ten nodes. This combustor model can be used to evaluate temperature characteristics while the oxidizer and fuel are spreading along the $\mathrm{x}$-axis. The length of the inlet duct is $0.104 \mathrm{~m}$. The length and diameter of combustor are $3.505 \mathrm{~m}$ and $0.00508 \mathrm{~m}$ respectively. Table 1 shows the specifications of the combustor model.

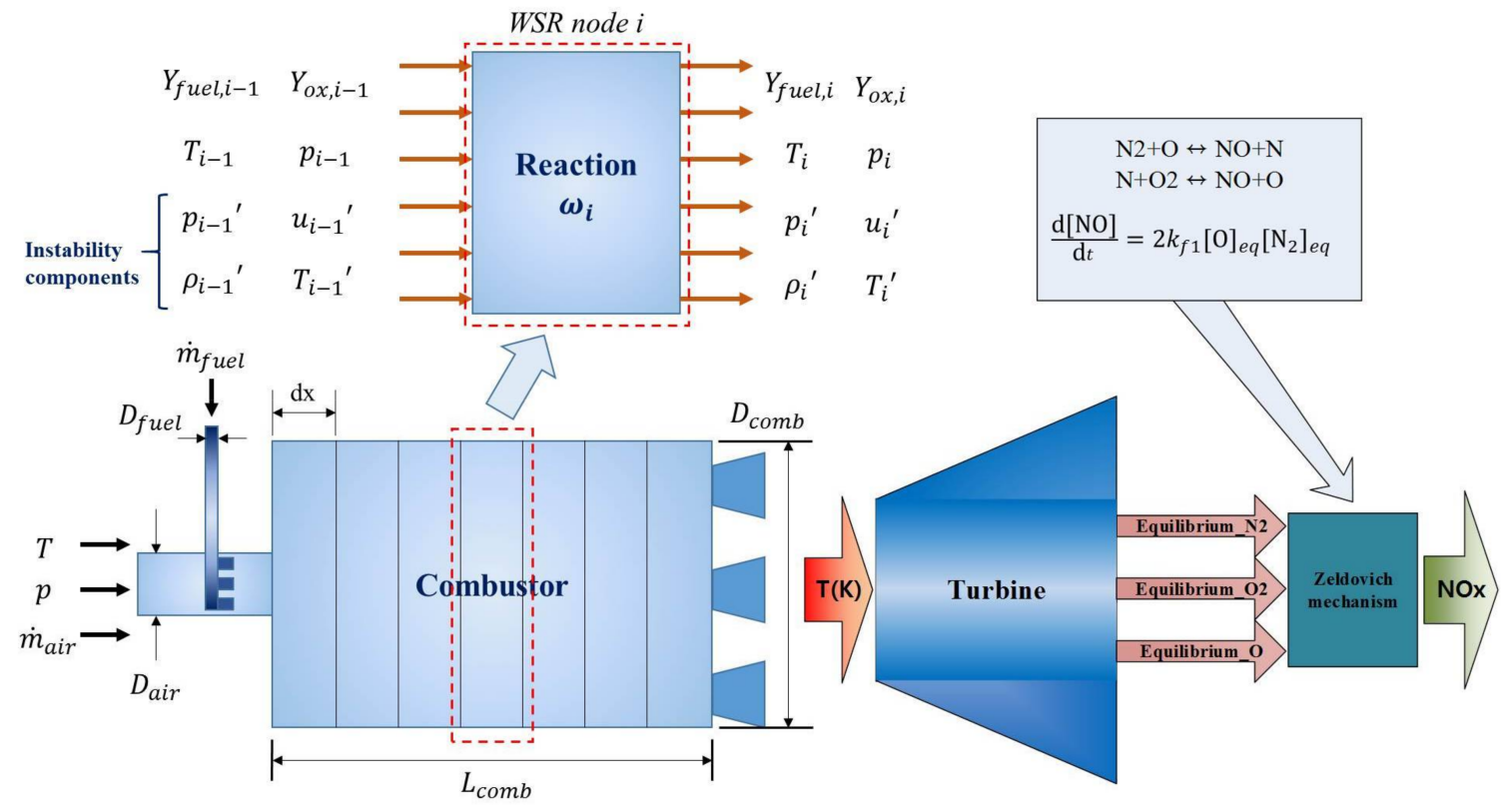

Figure 1. Schematic view of the combustor in a gas turbine. 
Table 1. Specifications of the combustor.

\begin{tabular}{ccl}
\hline Parameters & Value & Unit \\
\hline Equivalence ratio & $0.45-1$ & $\mathrm{NA}$ \\
Combustor pressure & 1 & $\mathrm{bar}$ \\
Inlet length & 428 & $\mathrm{~mm}$ \\
Combustor diameter & 184 & $\mathrm{~mm}$ \\
Combustor length & 854 & $\mathrm{~mm}$ \\
\hline
\end{tabular}

\subsection{Operating Conditions}

The inlet flow condition, including physical properties, and the flow characteristics of oxidizer and fuel streams, are shown Tables 2 and 3. The reactants mass flow rate was $171.42 \sim 174.94 \mathrm{~g} / \mathrm{s}$, and were injected at a temperature of $700 \mathrm{~K}$. The combustor pressure was $1 \sim 20 \mathrm{~atm}$ and the equivalence ratio was $0.45 \sim 1$. The inlet velocity was $10 \sim 60 \mathrm{~m} / \mathrm{s}$.

Table 2. Elementary process reaction rate parameter.

\begin{tabular}{ccccc}
\hline Fuel & Pre-Exponential Factor & Activation Temperature $\mathbf{E}_{\mathbf{a}} / \mathbf{R}_{\mathbf{u}}(\mathbf{K})$ & $\mathbf{m}$ & $\mathbf{n}$ \\
\hline $\mathrm{CH}_{4}$ & $1.3 \times 10^{8}$ & 24,358 & -0.3 & 1.3 \\
$\mathrm{CH}_{4}$ & $1.3 \times 10^{8}$ & 15,098 & -0.3 & 1.3 \\
$\mathrm{C}_{2} \mathrm{H}_{6}$ & $1.3 \times 10^{8}$ & 15,098 & 0.1 & 1.65 \\
$\mathrm{C}_{3} \mathrm{H}_{8}$ & $1.3 \times 10^{8}$ & 15,098 & 0.1 & 1.65 \\
\hline
\end{tabular}

Table 3. Inlet flow conditions of the combustor.

\begin{tabular}{ccc}
\hline Parameters & Value & Unit \\
\hline Inlet velocity & $10-60$ & $\mathrm{~m} / \mathrm{s}$ \\
Reactants mass flow rate & $171.42-174.94$ & $\mathrm{~g} / \mathrm{s}$ \\
Air density & 0.4991 & $\mathrm{~kg} / \mathrm{m}^{3}$ \\
Temperature & 700 & $\mathrm{~K}$ \\
Pressure & $1-20$ & $\mathrm{bar}$ \\
\hline
\end{tabular}

\subsection{Model Assumptions}

The assumptions used to define this analytical combustor model are as follows:

1. The air-fuel ratio is the same from the fuel injection to the combustion flame.

2. The heat transfer in control volume of the combustor wall is neglected.

3. The control volume of node is determined from the equilibrium temperature and steady state exit temperature.

4. The oxidizer and fuel reaction mechanism is one dimensional.

5. Product enthalpy is the sum of the enthalpy of formation and sensible enthalpy change.

\subsection{Governing Equation for the Combustor}

The governing equation for the fully mixed reactor consists of a continuity equation, energy conservation, kinetic equation, and species conservation equation. Since steady state flow is assumed and pressures are constant in this study, the kinetic equation is neglected. Thus, the continuity equation, energy conservation, and chemical species conservation were used in the WSR model.

The boundary condition of the combustor model assumes that the inlet equivalence ratio is constant. The fuel and the oxidant react by the chemical reaction rate, and the remaining mixture is transferred to the next node. 
The combustor is modeled by discretization to confirm combustion characteristics according to the position. For this purpose, each node is assumed to be a Well Stirred Reactor (WSR) and modeled to calculate the temperature by adiabatic process.

\subsubsection{Continuity Equation}

The chemical species conservation equation is in equilibrium with the atomic chemical. The total mass flow rate does not change, even if a product is produced by the reaction of the reactant. Therefore, the continuity equation can be expressed as

$$
\frac{d}{d t} \iiint_{V} \rho d V=0
$$

The integral continuity equation with WSR volume can be expressed as

$$
V \frac{d \rho}{d t}+\dot{m}-\dot{m}_{i n}=0
$$

Since the total flow rate in the control volume is the difference between the inlet flow rate and the outlet flow rate, the inviscid energy equation is calculated as

$$
\frac{d}{d t} \iiint_{V} \rho(e+\vec{u} \cdot \vec{u} / 2) d V=\oiint_{s} \vec{q} \cdot d \vec{S}-\oiint_{s} p \vec{u} \cdot d \vec{S}
$$

If the Mach number is much smaller than $1(\mathrm{M}<<1)$, Equation (3) is rewritten as follows:

$$
\iiint_{V} \frac{\partial(\rho e)}{d t} d V+\oiint_{s} \rho h \vec{u} \cdot \vec{S}=-\oiint_{s} \vec{q} \cdot \vec{S}
$$

Then, if the physical properties distribution in combustion chamber is uniform, Equation (4) is integrated against the WSR volume as follows:

$$
V \frac{d \rho e}{d t}+\dot{m} h-\dot{m}_{i n} h_{i n}=-Q_{L} A
$$

Here, the internal energy is expressed as

$$
e=h-\frac{p}{\rho}=h-\frac{R_{u}}{M W_{\text {mix }}} T=h-\sum_{j} \frac{Y_{j}}{M W_{j}} R_{u} T
$$

The internal energy equation is rewritten by combining Equation (2):

$$
\rho V \frac{d h}{d t}-\rho V \frac{d \sum_{j} \frac{j Y_{i} R_{u} T}{M W_{j}}}{d t}+\dot{m} \sum_{j} \frac{Y_{j} R_{u} T}{M W_{j}}+\dot{m}_{i n}\left(h-h_{i n}-\sum_{j} \frac{Y_{j} R_{u} T}{M W_{j}}\right)=Q_{L} A
$$

\subsubsection{Energy Conservation}

If the specific heat is constant, the enthalpy can be expressed as

$$
h=\sum_{j} h_{j} Y_{j}=\sum_{j} Y_{j}\left(h_{f, j}^{0}+c_{p, j}\left(T-T_{r e f}\right)\right)
$$


The above enthalpy equation is rewritten by combining Equation (7):

$$
\begin{gathered}
\rho V c_{p, m i x} \frac{\partial T}{\partial t}+\rho V \sum_{j} \frac{\partial Y_{j}}{\partial t}\left(h_{j}-\frac{R_{u} T}{M W_{j}}\right)+\dot{m} \sum_{j} \frac{Y_{j} R_{u} T}{M W_{j}} \\
+\dot{m}\left(h-h_{i n}-\sum_{j} \frac{Y_{j} R_{u} T}{j W_{i}}\right)=-Q_{L} A
\end{gathered}
$$

The last two terms of the left term can be combined into the continuity equation. Also, this assumes the heat transfer on the surface of a combustion chamber wall, the right term, which means energy loss is neglected. Finally, applying the ideal gas equation, Equation (9) is represented as the following:

$$
\frac{d T}{d t}=-\frac{1}{c_{p, \text { mix }}}\left[\sum_{j} \frac{d Y_{i}}{d t}\left(h_{j}-\frac{R_{u} T}{M W_{j}}\right)+\frac{\dot{m}_{i n}}{\rho V}\left(h-h_{i n}\right)-\frac{1}{\rho} \frac{d p}{d t}\right]
$$

As mentioned above, since the pressure is assumed to be constant to simulate steady state combustion, the last term in Equation (10) is zero. The temperature in the combustion chamber over time can be shown through the arranged energy conservation equation.

\subsubsection{Chemical Species Conservation}

Chemical species conservation is similar to the previously derived continuity equation. The chemical species conservation equation used in the model ignores diffusion because it is assumed to be a Well Stirred Reactor. However, convective terms exist. First, the integral chemical species conservation term can be expressed as

$$
\frac{d}{d t} \iiint_{V} \rho Y_{j} d V=\iiint_{V} \omega_{j} d V
$$

If the distribution of physical properties is uniform, Equation (11) is integrated with WSR volume and can be rewritten as

$$
V \frac{d \rho Y_{j}}{d t}+\dot{m} Y_{j}-\dot{m}_{i n} Y_{i, i n}=V \omega_{j}
$$

Equation (12) is rewritten by using the continuity equation, Equation (2):

$$
\frac{j Y_{i}}{d t}=\frac{\omega_{j}}{\rho}+\frac{\dot{m}_{i n}}{\rho V}\left(Y_{j, i n}-Y_{j}\right) \quad j=1, \cdots, n
$$

Thus, the total WSR governing equation can be summarized as follows:

$$
\begin{gathered}
\text { Mass : } \frac{d \rho}{d t}=\frac{1}{V}\left(\dot{m}_{i n}-\dot{m}\right) \\
\text { Energy : } \frac{d T}{d t}=-\frac{1}{c_{p, m i x}}\left[\sum_{j} \frac{d Y_{j}}{d t}\left(h_{j}-\frac{R_{u} T}{M W_{j}}\right)+\frac{\dot{m}_{i n}}{\rho V}\left(h-h_{i n}\right)-\frac{1}{\rho} \frac{d p}{d t}\right] \\
\text { Species : } \frac{d Y_{j}}{d t}=\frac{\omega_{j}}{\rho}+\frac{\dot{m}_{i n}}{\rho V}\left(Y_{j, \text { in }}-Y_{j}\right) \quad j=1, \cdots, n
\end{gathered}
$$

The chemical species conservation equation is categorized with the two following governing equations to capture the variation in the mass fraction rate of the oxidizer and fuel over time. Then, the product is expressed in equilibrium using the characteristics of the mass fraction. Fuel, oxidizer, and products were defined based on species conservation equation. Each species added the product at the node to the difference in the mass fraction of the node's inlet and outlet.

$$
\text { Fuel : } \rho V \frac{d Y_{f u e l}}{d t}=\dot{m}_{\text {in }} Y_{f u e l, i n}-\dot{m} Y_{f u e l}+M W_{f u e l} \dot{\omega}_{f u e l} V
$$




$$
\begin{gathered}
\text { Oxidizer : } \rho V \frac{d Y_{\text {oxid }}}{d t}=\dot{m}_{\text {in }} Y_{\text {oxid, in }}-\dot{m} Y_{\text {oxid }}+M W_{f u e l} \frac{Y_{\text {oxid, }, \text { in }}}{Y_{f u e l, i n}} \dot{\omega}_{f u e l} V \\
\text { Product : } Y_{\text {prod }}=1-Y_{\text {fuel }}-Y_{\text {oxid }}
\end{gathered}
$$

The dynamic behaviors of the WSR are characterized by the three governing equations presented above. Equation (14) represents the outlet flow rate of the fluid flow. Equation (15) shows the inflow rate and outflow rate of energy, and energy storage in the WSR. Equation (16) express the entry and consumption of each chemical species. In the case of the oxidizer, the consumption term is related to the fuel, because it is consumed proportionally with the fuel consumption ratio that is multiplied by air fuel ratio.

Since each equation has an algebraic relationship that participates in the right side of each other, it is necessary to determine an initial value. The mechanism of the chemical reaction rate used in the chemical species conservation equation was represented using an empirical equation. Westbrook and Dryer proposed and evaluated a single step, dual step, and multi steps overall reaction mechanism for the various changes in the many hydrocarbon compounds. In this study, only single step reaction mechanism was considered. This is because the chemical species of combustion reactants were identified using Cantera and made into a 3D-lookup table. This mechanism can be expressed as

$$
\begin{gathered}
\mathrm{C}_{x} \mathrm{H}_{y}+(x+y / 4) \mathrm{O}_{2} \rightarrow x \mathrm{CO}_{2}+(y / 2) \mathrm{H}_{2} \mathrm{O} \\
\omega_{i}=\frac{d\left[C_{x} H_{y}\right]}{d t}=-A^{a} \exp \left(\frac{-E_{a}}{R_{u} T}\right)\left[C_{x} H_{y}\right]^{m}\left[\mathrm{O}_{2}\right]^{n}
\end{gathered}
$$

\subsubsection{Quasi Steady State Model}

In Equation (15), using the enthalpy difference between the inlet and outlet of the control volume, however, has a critical limitation. It is because the effect of temperature variation on the equivalence ratio in the combustion chamber cannot be evaluated. For this reason, to satisfy the quasi steady state, composition data on the equivalence ratio in the exhaust combustion chamber is needed. In this study, a 3-D lookup table of various equivalence ratios of the equilibrium state, which was obtained from the Gas Chromatography test bench, was applied. The inputs are temperature, pressure, and equivalence ratio. Figure 2 shows the representative lookup table applied in this study.

The chemical composition table was made using the Cantera program and the data of the representative chemical species are shown in Figure 2. The chemical composition table can be used to analyze the adiabatic flame temperature and chemical composition with change in the inlet conditions of the combustor.

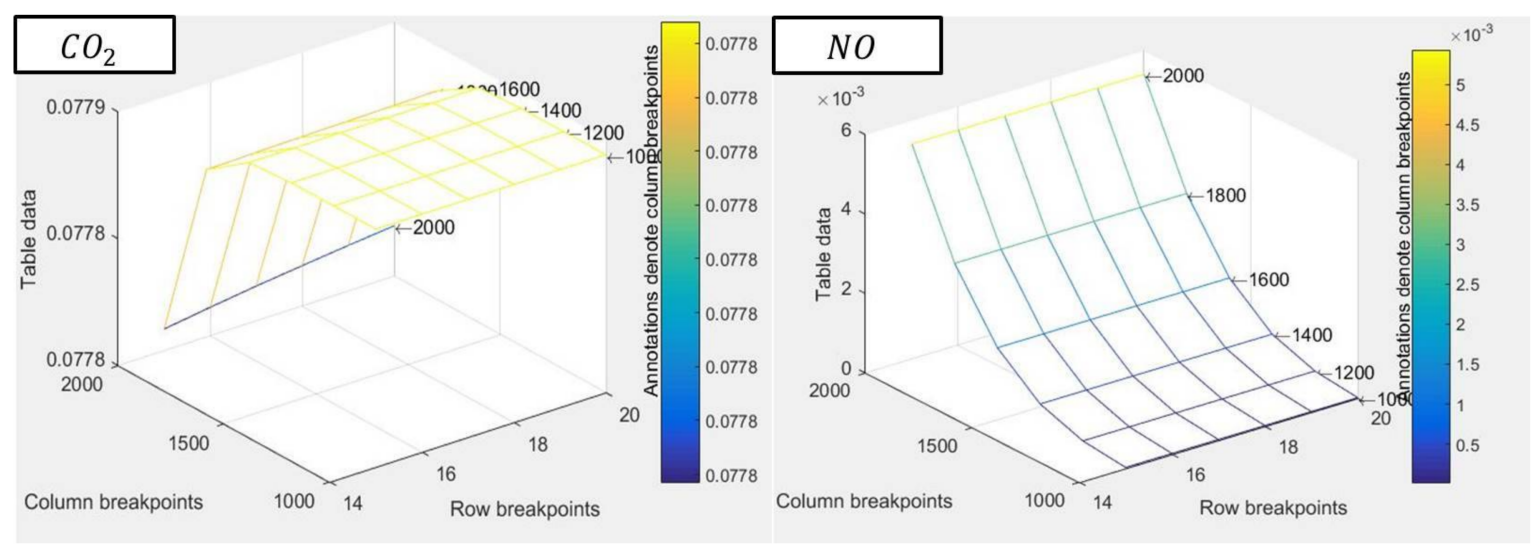

Figure 2. 3-D lookup table of various equilibrium states for temperature, pressure, and equivalence ratio. 


\subsubsection{Segment Combustor Model}

The segment technology is to construct a model with segmented nodes so that physical characteristics can be confirmed in each area. A node is an area of a combustor segmented for modeling.

In the case of a lumped combustor model, the combustion process in combustion chamber with region cannot assess. In the segment combustor model, however, dynamic behaviors such as temperature, chemical species density can be evaluated at each node. Also, the dynamic behaviors can be evaluated along the $x$-axis, while the oxidizer and fuel are propagating along the $x$-axis. For this reason, the segment technology was applied in this study, using 10 nodes. Thus, Equations (14)-(16) can be rewritten as

$$
\begin{gathered}
\text { Mass : } \frac{d \rho_{i}}{d t}=\frac{1}{V}\left(\frac{\dot{m}_{i+1, i n}+\dot{m}_{i-1}-2 \dot{m}_{i}-\dot{m}}{d x^{2}}\right) \\
\text { Energy }: \frac{d T_{i}}{d t}=-\frac{1}{c_{p, m i x}}\left[\begin{array}{c}
\sum_{j} \frac{d Y_{i, j}}{d t}\left(h_{j}-\frac{R_{u}\left(\frac{T_{i+1}+T_{i-1}+2 T_{i}}{d x^{2}}\right)}{M W_{j}}\right) \\
+\frac{\dot{m}_{i, i n}}{\rho d x}\left(h-h_{i, i n}\right)-\frac{1}{\rho_{i}} \frac{d p_{i}}{d t}
\end{array}\right] \\
\text { Species : } \frac{d Y_{i, j}}{d t}=\frac{\omega_{i, j}}{\rho_{i}}+\frac{\dot{m}_{i, i n}}{\rho_{i} V}\left(\frac{Y_{i, i n}-\left(Y_{j+1, i}+Y_{j-1, i}-2 Y_{j, i}\right)}{d x^{2}}\right) \quad j=1, \ldots, n
\end{gathered}
$$

Figure 3 shows a schematic diagram of the segmented combustor model and Table 4 shows the length of the regions and nodes.

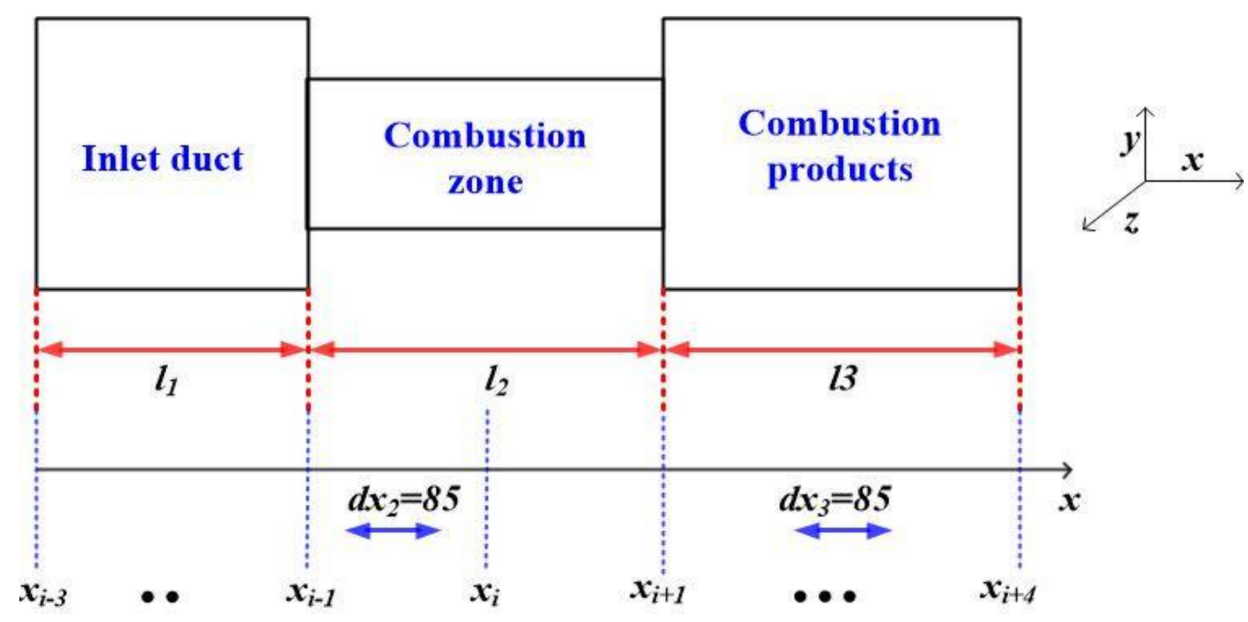

Figure 3. Sketch of the segment combustor model with nodal positions.

Table 4. Length of regions and nodes.

\begin{tabular}{ccl}
\hline Parameters & Value & Unit \\
\hline$l_{1}$ & 428 & $\mathrm{~mm}$ \\
$l_{2}+l_{3}$ & 854 & $\mathrm{~mm}$ \\
$d x_{2}$ & 85 & $\mathrm{~mm}$ \\
$d x_{3}$ & 85 & $\mathrm{~mm}$ \\
\hline
\end{tabular}

\section{Thermo-Acoustic Combustion Instability Model}

To establish a combustion instability model for a gas turbine, it is important to understand the conceptual framework of the combustion instability phenomena observed in the gas turbine. In this section, the derivation of this model will be presented. The heat release in the developed combustion instability model was expressed using a simplified $n-\tau$ model, so the chemical reaction was neglected. The parameters of the thermo-acoustic combustion instability model are the same as 
those of the combustor model. This is because the result of the combustor model is used as input to the thermo-acoustic combustion instability model.

In the proposed model, to evaluate the combustion process in detail by region, the combustion process was divided into three regions. For example, the flow stream effect and pressure oscillations are dominant in regions I and III. On the other hand, in region II, heat release, which is caused by chemical reactions, dominates. For these reasons, the thermo-acoustic combustion instability model consisted of three connected regions, as shown in Figure 4. Region I represented the air inlet duct and the fuel supply region, region II was the circulation zone where the combustion takes place, and region III was the product area containing the exhaust gas.

The inlet and outlet of the combustion system have boundary conditions that the perturbation must satisfy. If the inlet is supplied by a large plenum chamber, the pressure perturbation can be modeled by taking $p^{\prime}=0$. If the outlet is vented to atmosphere or a large plenum chamber, it can be modeled as an open end by taking $p^{\prime}=0$.

The governing equations in each region are different and discretized to express the combustion instability propagation in the combustor.

The heat release region is set as one node, and the combustion instability is amplified through the boundary condition of the flame surface.

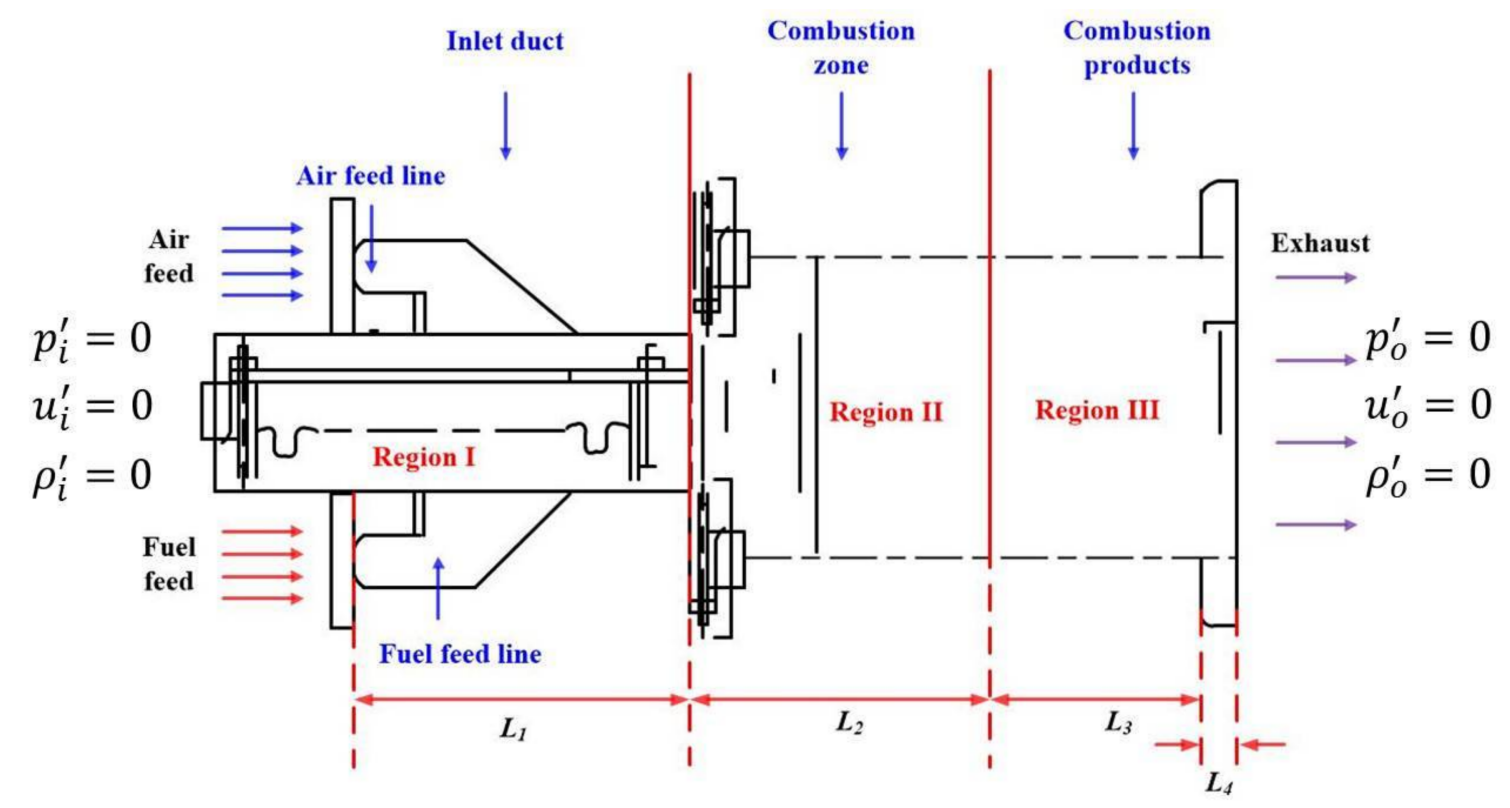

Figure 4. Schematic view of the combustor in a gas turbine.

The key assumptions in this model are as follows:

1. An inviscid, ideal gas.

2. The mean flow has low Mach number.

3. The length of the flame is much smaller than the length of the wavelength.

4. The mean flow fields in regions (1) and (3) are uniform.

5. The mean flow fields in regions (1) and (3) are isentropic.

6. The acoustic fields in regions (1) and (3) are one-dimensional.

\subsection{Combustion Chamber Wave Equation (I, III Regions)}

As mentioned above, the flow stream effect and pressure oscillations are dominant in regions I and III. For this reason, the continuity equation, momentum equation, and energy equation are used in these regions. Also, assumption 6 was applied to derive the wave equation, because turbulence or 
disturbance is well propagated and appears along the $x$-axis. In addition, the relationship between the square of the Mach number $\left(M^{2}\right)$ and flame length and acoustic wavelength $\left(L_{f l a m e} / \lambda\right)$ was neglected [29]. Thus, the general governing equation can be defined as

$$
\begin{gathered}
\text { Mass : } \frac{\partial \rho^{\prime}}{\partial t}+\bar{\rho} \frac{\partial u^{\prime}}{\partial x}+\bar{u} \frac{\partial \rho^{\prime}}{\partial x}=0 \\
\text { Momentum : } \bar{\rho} \frac{\partial u^{\prime}}{\partial t}+\overline{\rho u} \frac{\partial u^{\prime}}{\partial x}=-\frac{\partial \rho^{\prime}}{\partial x} \\
\text { Energy : } \frac{1}{\bar{\rho}}\left(\frac{\partial \rho^{\prime}}{\partial t}+\bar{u} \frac{\partial \rho^{\prime}}{\partial x}\right)=\frac{1}{\gamma \bar{p}}\left(\frac{\partial \rho^{\prime}}{\partial t}+\bar{u} \frac{\partial^{\prime} p}{\partial x}\right)
\end{gathered}
$$

Therefore, the disturbance equations in these regions I and III can be rewritten by combining Equations (25)-(27):

$$
\left(\frac{\partial}{\partial t}+\bar{u} \frac{\partial}{\partial x}\right)^{2} p^{\prime}-\bar{c}^{2} \frac{\partial^{2} p^{\prime}}{\partial x^{2}}=0
$$

\subsection{Combustion Chamber Heat Release Equation (II Region)}

Equation (28) requires a relationship between pressure oscillation and heat release rate oscillation. In this study, to model the heat release equation, the following key assumptions are listed:

1. The chemical reaction rate is faster than the flow rate on the flame plane (Damkohler number is infinite).

2. The mean flow rate of turbulence levels is not influenced by the heat release term.

3. The inlet fuel flow rate is various.

4. The boundary condition at the inlet and outlet is $p^{\prime}(0)=u^{\prime}(L)=0$

5. The boundary conditions at the flame area $(\mathrm{x}<\mathrm{b}$ and $\mathrm{x}>\mathrm{b})$ are $\left[p^{\prime}\right]_{x=b^{-}}^{x=b^{+}}=0$ and $\left[\frac{\partial p^{\prime}}{\partial x}\right]_{x=b^{-}}^{x=b^{+}}=-\frac{\gamma-1}{\bar{c}^{2}} \frac{d Q^{\prime}}{d t}$.

Since the chemical reaction rate is faster than the flow rate and choked flow at the inlet of the combustor, the assumption of the model is reasonable. Also, because the model is modeled by the heat release equation ignoring the area of the flame, the assumption (4) is also valid.

Then, the fluctuation in the heat release rate (source term) can be expressed by the $n$ - $\tau$ model [30]

$$
\begin{gathered}
Q^{\prime}(t)=\left(\bar{\rho}_{1} \bar{c}_{1}{ }^{2} / \gamma-1\right) n u^{\prime}(t-\tau) \\
q^{\prime}(x, t)=Q^{\prime}(t) \delta(x-b)
\end{gathered}
$$

The velocity perturbation $u^{\prime}$ in the fluctuation in the heat release equation can be calculated as

$$
u^{\prime}=\varepsilon u_{1} \sin \omega t
$$

where $\varepsilon$ is the relative intensity of the fluctuation, and $\omega$ is the frequency of the acoustic field. Note that the overall velocity space is given by $u=\bar{u}+u^{\prime}$.

The interaction index describes the correlation between the perturbation in the velocity and fluctuation of the heat release rate. Thus, the interaction index can be expressed as

$$
n=\frac{2 \bar{Q}}{G^{2} u_{1}} \times \sqrt{(1-\cos G)^{2}+G^{2}\left(1-\frac{1}{G} \sin G\right)^{2}}
$$


Since heat release is related to temperature gradients, mean temperature, and density, an entropy equation should be calculated as follows:

$$
\rho T(S(\partial / \partial t+u \cdot \nabla))=q
$$

The ideal gas approach can be used to replace entropy. Then Equation (33) can be rewritten as

$$
\frac{\rho T c_{v}}{p}(p(\partial / \partial t+u \cdot \nabla))=-c_{p} T(\rho(\partial / \partial t+u \cdot \nabla))+q
$$

Equation (33) is rewritten by combining the mass conservation equation.

$$
p(\partial / \partial t+u \cdot \nabla)=c^{2} \rho \nabla \cdot u+(\gamma-1) q
$$

Equation (28) can be represented by combining a linearized Equation (35), and the entropy equation.

$$
\frac{1}{\bar{c}^{2}} \frac{\partial^{2} p^{\prime}}{\partial t^{2}}-\frac{\partial^{2} p^{\prime}}{\partial x^{2}}=\frac{\gamma-1}{\bar{c}^{2}} \frac{\partial q^{\prime}}{\partial t}
$$

Equation (36) is the heat release equation, the term on the right-side source term, which describes how the unsteady heat addition causes pressure instability.

Unstable heat release in the combustion zone causes acoustic perturbation and acoustic perturbation propagates to the surroundings. The generated acoustic perturbation propagates to the inlet flow, which affects the change of the input flow rate and equivalence ratio. The affected flow again makes a perturbation of the instability mechanism causing unstable heat release.

\subsection{Convection Time Delay}

In the current model, the time delay was defined by the heat release rate and flame strouhal number:

$$
\tau=\frac{1}{\omega} \tan ^{-1}\left[\frac{G\left(1-\frac{1}{G} \sin G\right)}{1-\cos G}\right]
$$

The convection time delay is independent of the perturbation of velocity. Then, the variable $G$ is expressed by the flame strouhal number as follows:

$$
G=\omega R / S_{u}
$$

where $S_{u}$ is the laminar burning velocity.

\subsection{Segment Combustor Instability Model}

The segment model was expressed in a segment form to detect the combustion instability according to the position of the combustor. In addition, it made in the segment model to represent the instability propagation by applying the finite difference method as Figure 5 .

The segment combustion instability can be used to evaluate the effect of the combustion instability at the location of each node.

The dynamic behaviors can be evaluated along the x-axis, while the oxidizer and fuel are propagating along the $x$-axis. For this reason, the segment technology was applied in this study, and the node number for the combustion instability was 8 nodes. Thus, Equations (25)-(27) can be rewritten as

$$
\frac{\partial^{2} p^{\prime}}{\partial x^{2}{ }_{(i+0.5)}}=\frac{p_{i+1}^{\prime}+p_{i-1}^{\prime}-2 p_{i}^{\prime}}{\left(\Delta x^{2}\right)}
$$




$$
\frac{\partial^{2} p^{\prime}}{\partial t^{2}}=\bar{c}^{2}\left(\frac{p_{i+1}^{\prime}+p_{i-1}^{\prime}-2 p_{i}^{\prime}}{\left(\Delta x^{2}\right)}\right)+(\gamma-1) \frac{\partial q^{\prime}}{\partial t}
$$

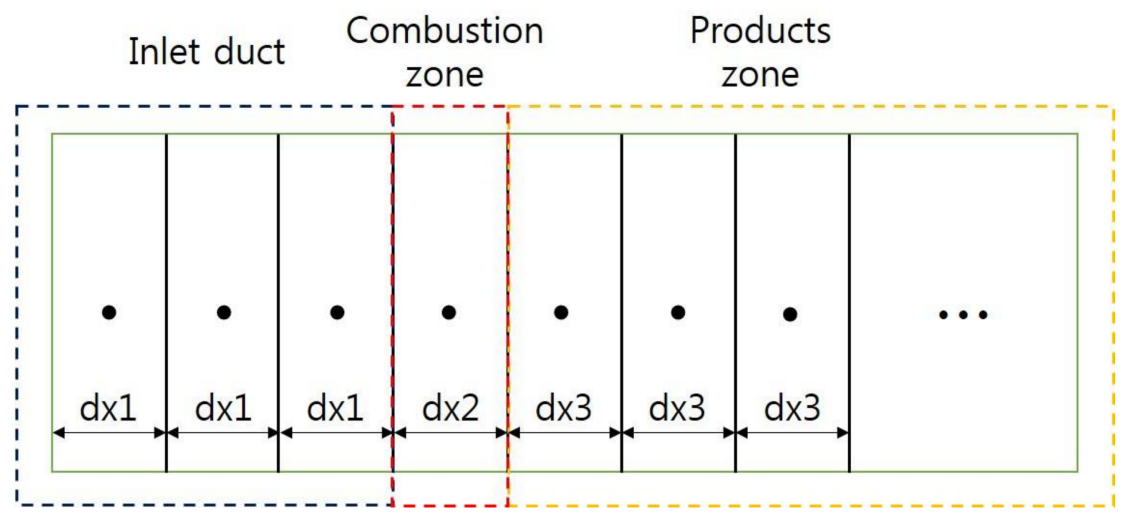

Figure 5. Sketch of the segment combustion instability with nodal positions.

\section{Results and Discussion}

\subsection{Comparisons of Model Results with Experimental Data}

To verify the designed combustor model, it was validated using experimental data for the atmospheric pressure test of the gas turbine performed by a certain company. The nozzle data from the model was compared with the air inlet data of a single nozzle combustor, and the combustor data in the model was compared with the pressure data in the region where there is flame in the nozzle combustor. Figure $6 \mathrm{a}, \mathrm{b}$ shows the validation results of the frequency domain. The amplitude with frequency agreed well with the experimental data when the frequency was lower than $300 \mathrm{~Hz}$. Experiments and model errors at high frequencies are modeled by ignoring high frequencies because the main combustion instability amplitude occurs at low frequencies.

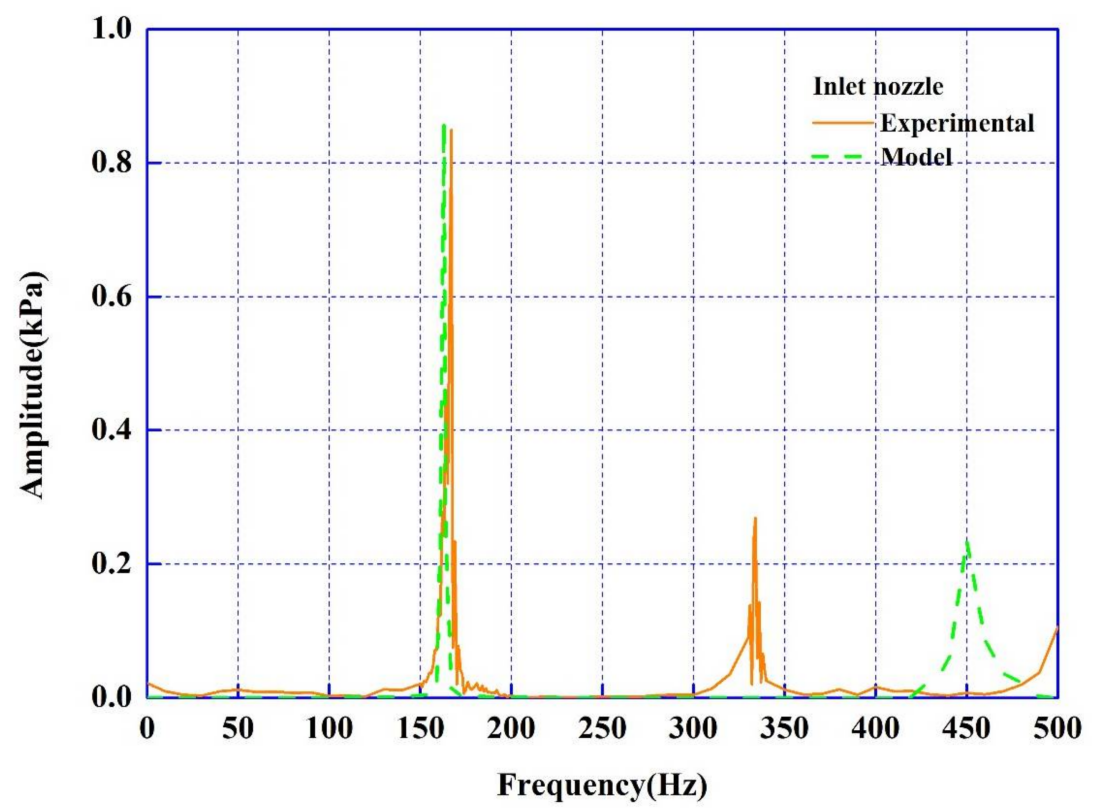

(a)

Figure 6. Cont. 


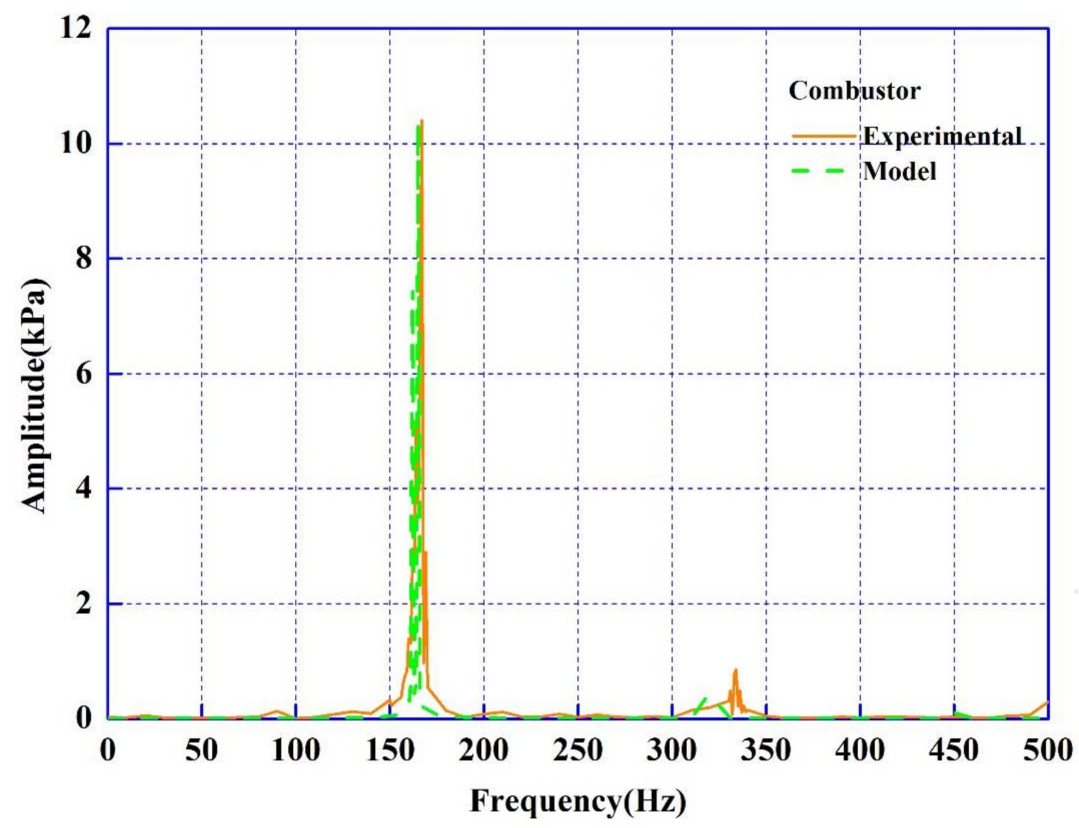

(b)

Figure 6. Comparison of pressure instability in the combustor in the frequency domain ((a) inlet duct nozzle, (b) combustor nozzle).

\subsection{Optimal Nodal Identification}

In this section, the segmented combustor model was simulated to identify the optimal node number. The adiabatic flame temperature response is affected by the node number due to the chemistry reaction rate. Figure 7 shows the adiabatic flame temperature settling time with node number. The settling time of the adiabatic flame temperature decreases with increasing node number, since the total volume is segmented. For this reason, the activation volume, which occurs in the chemistry reaction region, was reduced. As a result, the chemistry reaction rate was accelerated in the combustor.

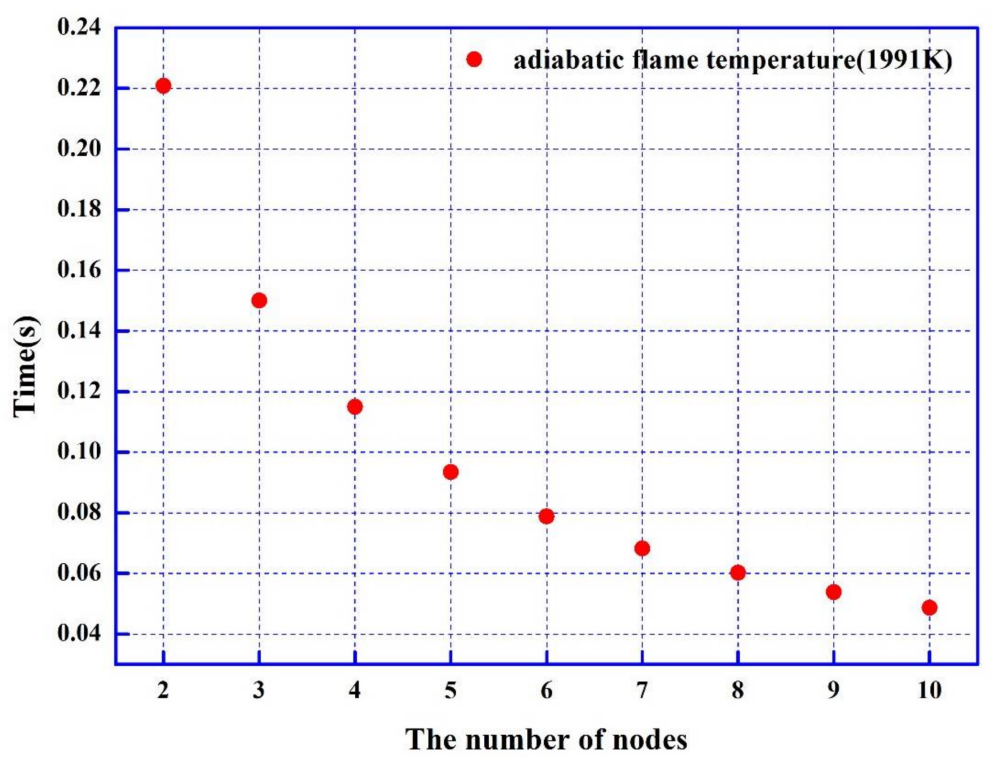

Figure 7. Adiabatic flame temperature settling time with node number. 
If a segment has more than 10 nodes, the adiabatic flame temperature response is no longer improved due to the physical phenomenon. Therefore, the optimal settling time is $0.01 \mathrm{~s}$, and the optimal node number was selected to be 10 in this study. At this time, the adiabatic flame temperature does not change with the node number. This is because temperature evolution for the air and fuel into the combustor inlet does not change. Since the reaction rate in the chemical reaction zone is inversely proportional to the volume, it is possible to increase the responsiveness of the model by selecting the optimal number of nodes.

\subsection{Combustor Model Validation}

The validity of the model was confirmed by comparing the adiabatic flame temperature of the developed model with the temperature of the commercial program GASEQ as Figure 8. When the equivalence ratio was changed from 0.5 to 1 , the difference between the two results was up to $6 \%$. This error is due to the assumption of WSR when designing the model. Also, the cause of the error is that the chemical species of the product are made into 3D-lookup table and applied. This verified the validity of the model.

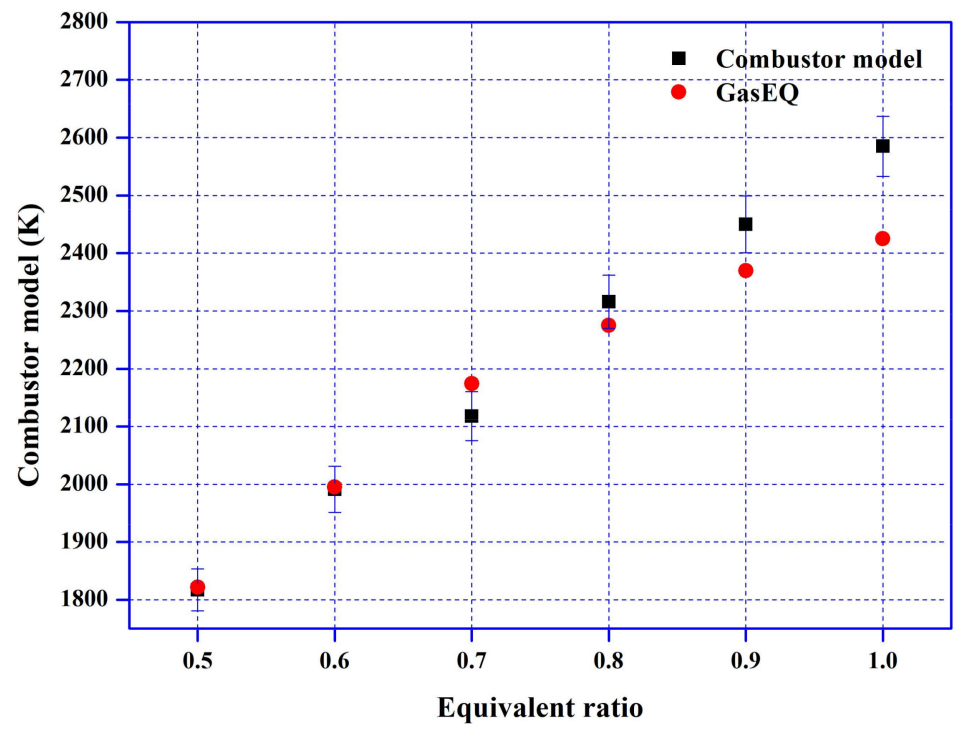

Figure 8. Combustor model validation with GasEQ.

\subsection{Combustor Transient Simulation}

Figure $9 \mathrm{a}, \mathrm{b}$ shows the combustor transient simulation for combustion. The equivalence ratio was changed during the simulation. The change in equivalence ratio was made using the Simulink program's Step block to change the fuel and oxidant. Since the combustor is set as a Well Stirred Reactor, there is no physical drawback.

The inlet equivalence ratio is 0.89 , pressure is $10 \mathrm{~atm}$ and the temperature in the combustor is $298.15 \mathrm{~K}$, respectively. As shown in Figure 9a, the temperature sharply increases and then the temperature reaches a steady state. The combustion temperature remained at $2139 \mathrm{~K}$ due to the constant operating condition.

Also, the transient response of the temperature with various equivalence ratios is shown in Figure $9 \mathrm{~b}$. The equivalence ratio was changed from 1 to 0.7 to ensure the combustor stability. As shown in Figure $9 b$, the combustion temperature decreased with decreasing equivalence ratio, since the energy density that can be burned decreases with decreasing equivalence. If the combustor is adiabatic, the temperature of the combustor model represents the adiabatic flame temperature. In addition, since the combustor is assumed to be a Well Stirred Reactor (WSR), it is considered that the instantaneous temperature is changed according to the change of the equivalence ratio. 


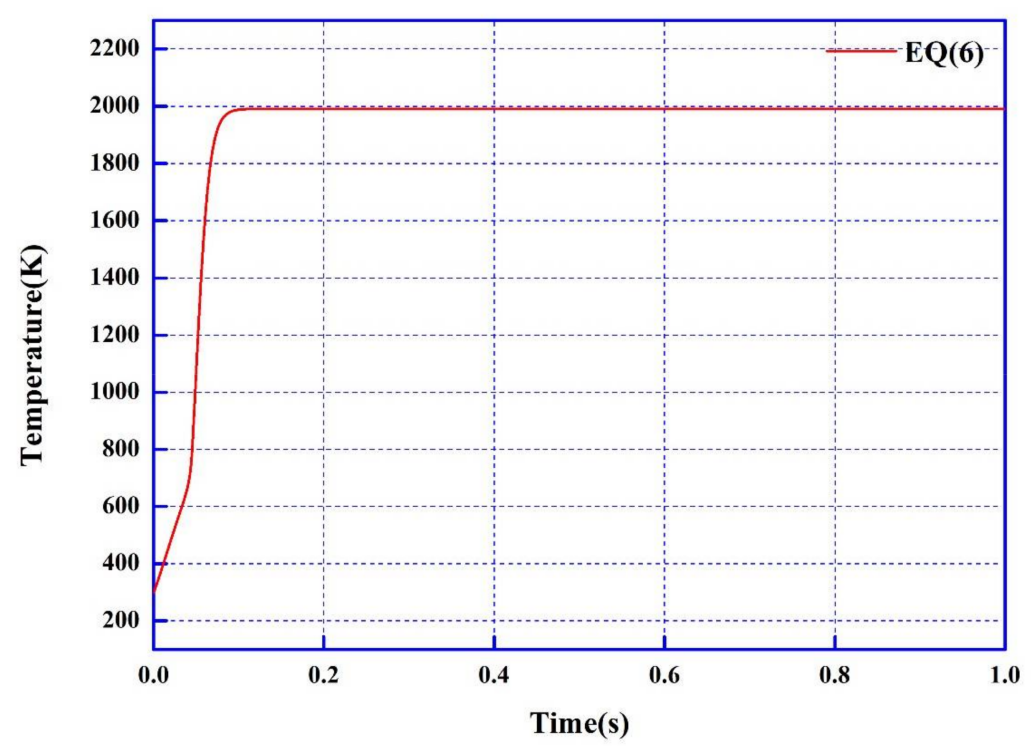

(a)

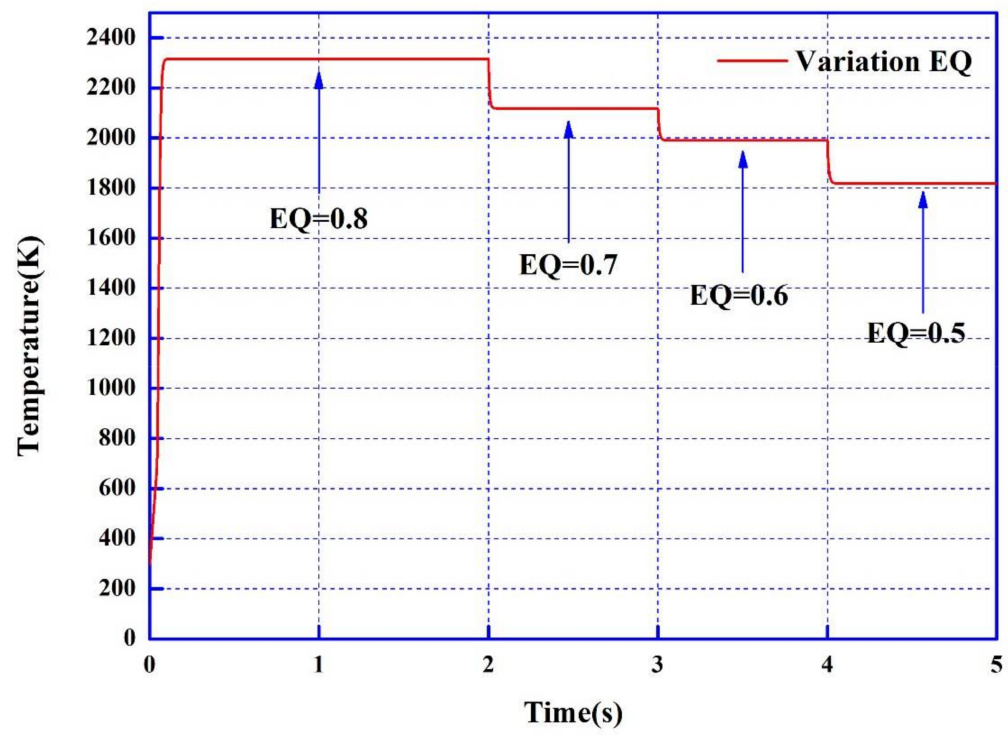

(b)

Figure 9. The transient WSR temperature response ((a) constant input condition $(\phi=0.89, p=10 \mathrm{~atm})$, (b) combustor nozzle ( $\phi=1$ to $0.7, p=10 \mathrm{~atm})$ ).

\subsection{Combustion Instability for the High Pressure Mode}

\subsubsection{Pressure Instability with Equivalent Ratio}

Figure 10 shows the instability amplitude of each node with the change in the equivalence ratio. Nodes 1, 2, and 3 are the nozzles of the inlet duct. There is little pressure perturbation in node 1 even when the equivalence ratio is changed. This is because the flame does not exist in node 1 . For this reason, amplification of the flow fluctuation does not occur in this zone. Because the compressor outlet of the gas turbine can be modeled as a choked flow to the combustion system. Node 4 is a combustion zone where flame is generated due to the heat generated by combustion. For this reason, a pressure perturbation occurs, and the amplitude is larger than the other nodes, due to flame. As the equivalence ratio increases, the amplification of the pressure perturbation increases. That is why the 
heat generation increased in node 4 . Nodes 5 to 9 are the region where there are products. This is because the amplification of the pressure in node 2 is propagated to node 3 .

As shown in Figure 10, the amplitude decreased at larger node numbers downstream. That is the reason the combustion outlet is directly connected to the ambient. Since there is no combustion instability at the end of the combustor, the amplitude decreased more when the equivalence ratio was larger. As a result, a high equivalence ratio generally resulted in a reduction rate of $78 \%$. On the other hand, the 0.5 equivalence ratio generally had a reduction rate of $68 \%$. A finite difference method was applied to express the propagation of the pressure perturbation. Since the pressure perturbation is a function of heat release, it is considered that the amplitude increase as the equivalence ratio increases. The pressure perturbation amplified by the flame propagates in the $\mathrm{x}$ direction, and the amplitude is reduced by the boundary conditions.

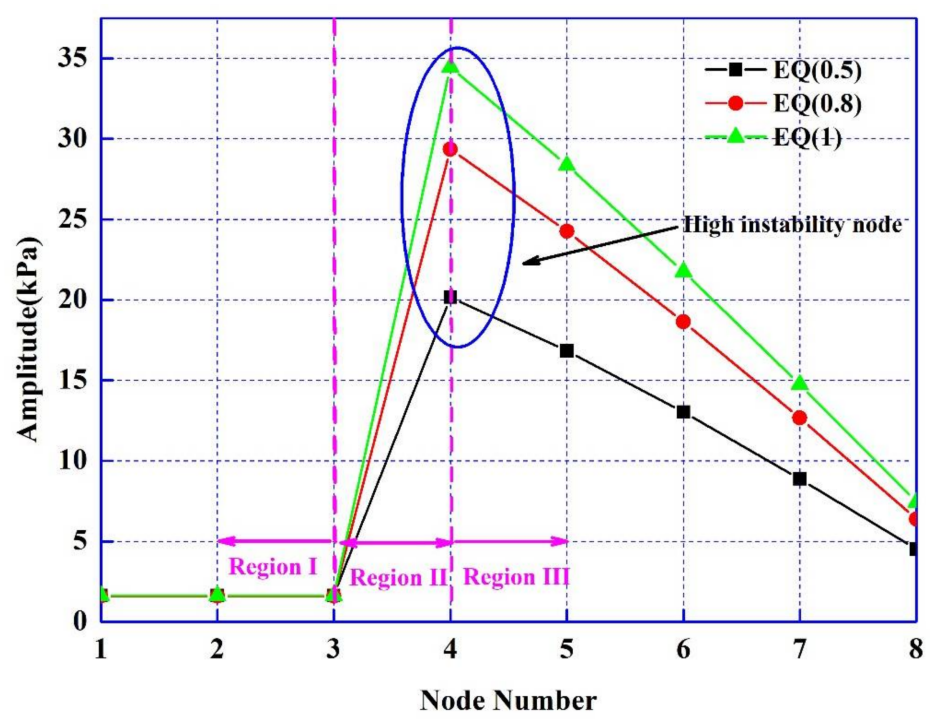

Figure 10. Instability amplitude of each node with various equivalence ratios.

\subsubsection{Pressure Instability with Load Variation}

Figure 11 shows the instability amplitude of each node with the variation in load. The $100 \%$ load was assumed to be the combustion reaction of the combustor test operation. The amount of air and the fuel changed so that the equivalence ratio was constant. As in the previous figure, the low-pressure perturbation occurred in nodes 1,2 , and 3 . Then, node 4 had a higher amplitude value than the other nodes, because of the flame generated by combustion. When the load changed, it had a lower amplitude value of $38 \%$ than the case of an equivalence ratio change. This is because the heat generation is dominantly influenced by the adiabatic flame temperature, which is influenced by the equivalence ratio. Hence, there is a lower amplitude value in the case of a load change than in the case of an equivalence ratio.

As shown in Figure 11, a high load has a higher amplitude value than a low load. This is because the difference of amount of the total concentration in the region II. Generally, if the load decreases, the amount of air and fuel also decrease due to constant equivalence ratio. For this reason, the total concentration reduces, and the density also decreases. As a result, the variation in the equivalence ratio more strongly influenced the pressure instability than the variation in load. 


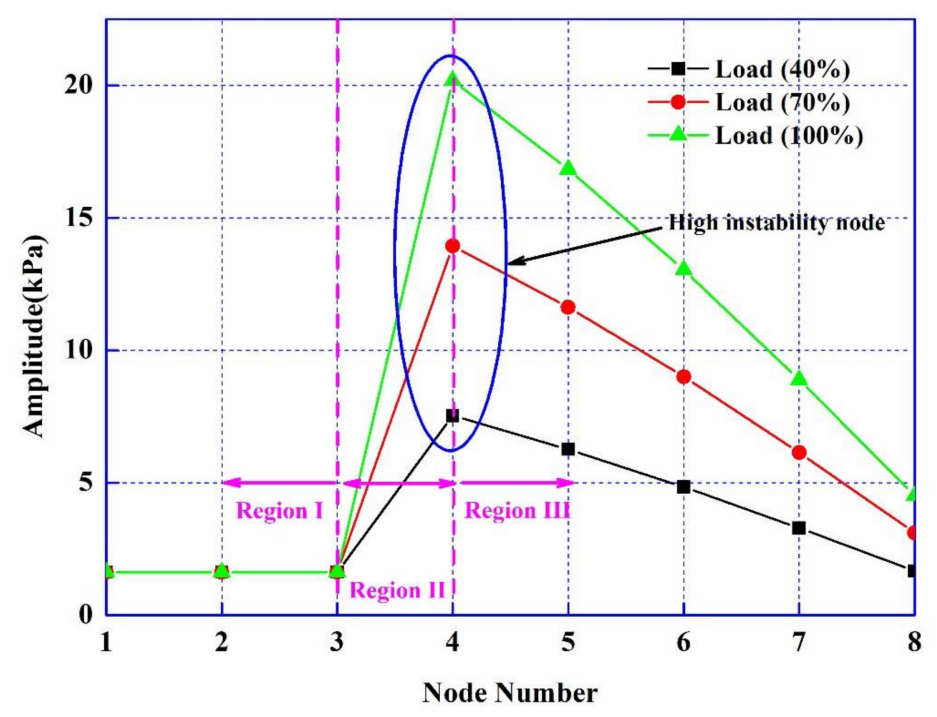

Figure 11. Instability amplitude of each node with various loads.

\subsubsection{Pressure Instability with Variation in Inlet Pressure}

The combustion instability also affects for the case with different inlet pressure as shown in Figure 12. If the pressure increases, the amplitude size also increases. This is because the density of the air and the fuel increases. Unlike the case of the varying load and equivalence ratio, the difference in amplitude with varying inlet pressure is small. That is the reason the density does not have a big influence on the combustion instability. In addition, at node 6, there is little difference in the inlet pressure due to the influence of the boundary condition. As a result, the change in pressure has the least effect on combustion instability.

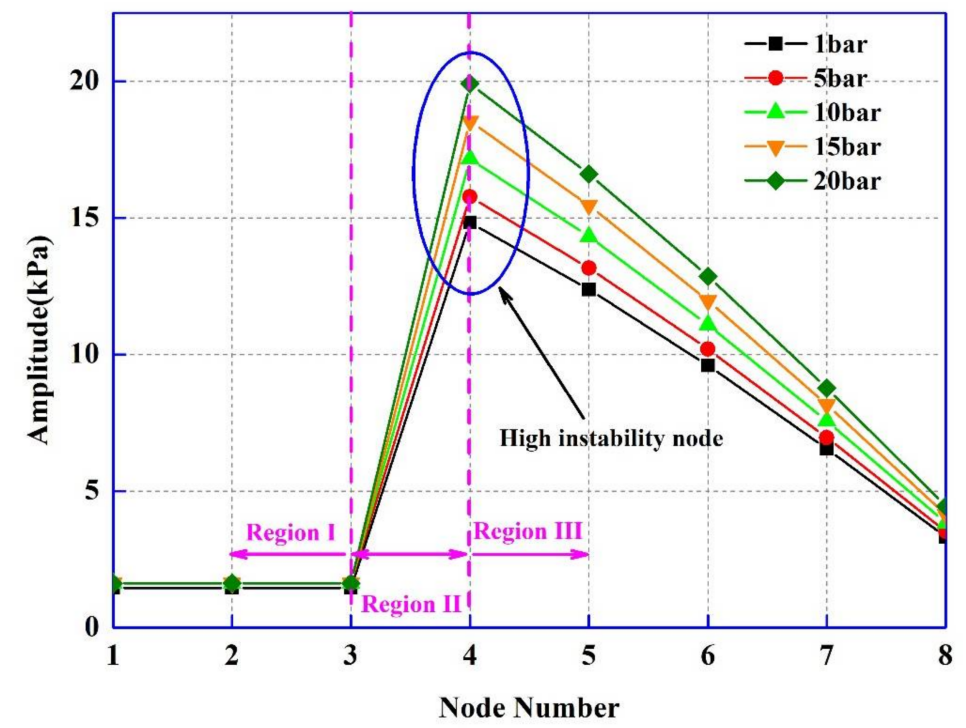

Figure 12. Instability amplitude of each node with various inlet pressures.

\section{Conclusions}

In this study, a segmented combustor model was developed to evaluate the dynamic characteristics of the combustor. Then an acoustic heat release model was implemented in the 
combustor dynamics to predict the instability amplitude at the nodes using the segment method. The major results can be summarized as follows:

(1) An acoustic heat release model developed using Matlab/Simulink ${ }^{\circledR}$ was implemented into a quasi-state combustor model using the segment method. A 3-D look up table used in the combustor mode, which utilized the WSR model to design a quasi-steady state. The combustor model has a maximum error of $6 \%$ compared to commercial program GASEQ. This confirms the validation of the model. The optimal nodal number was determined as the stabilization time of the adiabatic flame temperature.

(2) An instability mechanism model was developed. The combustion instability was segmented into eight nodes and six control volumes in the axial direction to evaluate the process of flame propagation at each node. The designed combustion instability model was validated using experiment data to verify the instability characteristics.

(3) The optimal nodal number for the segmented combustor model was identified. The optimal number of nodes was determined to be ten in this study, since the adiabatic flame temperature response was no longer improved for more than ten nodes.

(4) The combustion instability model was simulated to investigate the dynamic instability amplitude of the equivalence ratio, temperature, and pressure. At the first node, there was little instability amplitude because there was no flame. Node 4 had the highest instability amplitude because a flame was generated due to the heat generated by combustion. Then, the instability amplitude was decreased in nodes 5 to 8 by the product zone.

(5) The combustion instability amplitude was confirmed by the change of the equivalence ratio, load, and inlet pressure. As those are increased, the combustion instability amplitude also increased. Among them, the amplitude with the change of the equivalence ratio was the greatest increase because the effect of heat release was the greatest.

Acknowledgments: This research was supported by Basic Science Research Program through the National Research Foundation of Korea (NRF) funded by the Ministry of Science, ICT and Future Planning (No. 2017R1A2B4006528). This work was supported by the Technology Innovation Program (10082569, The Development of $5 \mathrm{~kW}$-class SOFC-Engine Hybrid System technology for field test) funded by the Ministry of Trade, Industry \& Energy (MOTIE, Korea).

Author Contributions: All authors contributed to this research in collaboration. Jaeyoung Han designed the model, and Jiwoong Jeong validated the model with experimental data, Kyungin Cho provided substantial help with the experimental setup, and Sangseok Yu provided substantial help with the paper schedule and implemented the proposed combustion instability.

Conflicts of Interest: The authors declare no conflict of interest.

\section{Nomenclature}

$\begin{array}{ll}A & \text { Area }\left[\mathrm{m}^{2}\right] \\ A_{f} & \text { Pre-exponential factor }\left[\mathrm{g} \cdot \mathrm{mol} \cdot \mathrm{cm}^{-3} \cdot \mathrm{s}^{-1}\right] \\ C_{p} & \text { Specific heat capacity }\left[\mathrm{J} \cdot \mathrm{kg}^{-1} \cdot \mathrm{K}^{-1}\right] \\ c & \text { Sound velocity }\left[\mathrm{ms}^{-1}\right] \\ E_{a} & \text { Activation energy }\left[\mathrm{kJ} \cdot \mathrm{g} \cdot \mathrm{mol}^{-1}\right] \\ e & \text { Internal energy }[\mathrm{kJ}] \\ G & \text { Flame strouhal number }[-] \\ H & \text { Enthalpy }\left[\mathrm{kJ} \cdot \mathrm{kg}^{-1}\right] \\ m & \text { Mass flow rate }\left[\mathrm{kg} \cdot \mathrm{s}^{-1}\right] \\ M W & \text { Molecular weight }\left[\mathrm{kg} \cdot \mathrm{kmol}{ }^{-1}\right] \\ n & \text { Interaction index }[-] \\ p & \text { Pressure }[\mathrm{kPa}] \\ Q & \text { Heat release rate }\left[\mathrm{kJ} \cdot \mathrm{s}^{-1}\right] \\ q & \text { Heat of reaction per unit mass of mixture }\left[\mathrm{kJ} \cdot \mathrm{kg}^{-1} \cdot \mathrm{s}^{-1}\right]\end{array}$




$\begin{array}{ll}R & \text { Radius }[\mathrm{m}] \\ S & \text { Entropy }\left[\mathrm{kJ} \cdot \mathrm{kg}^{-1} \cdot \mathrm{K}^{-1}\right] \\ S_{u} & \text { Laminar burning velocity }\left[\mathrm{ms}^{-1}\right] \\ T & \text { Temperature }[\mathrm{K}] \\ t & \text { Time }[\mathrm{s}] \\ \tau & \text { Time delay }[\mathrm{s}] \\ u & \text { Average of the mean flow }\left[\mathrm{ms}^{-1}\right] \\ V & \text { Volume }\left[\mathrm{m}^{3}\right] \\ \omega & \text { Acoustic mode frequency }[\mathrm{Hz}] \\ \psi & \text { Mass fraction } \\ \rho & \text { Density }\left[\mathrm{kg} \cdot \mathrm{m}^{-3}\right]\end{array}$

\section{Subscripts and Superscripts}

$\begin{array}{ll}\text { fuel } & \text { fuel } \\ i & \text { Chemical species } \\ \text { in } & \text { Inlet flow } \\ \text { mix } & \text { Mixture } \\ \text { oxid } & \text { Oxidizer } \\ \text { prod } & \text { Products } \\ \text { ref } & \text { Reference }\end{array}$

\section{References}

1. Krieger, G.C.; Campos, A.P.V.; Takehara, M.D.B.; Cunha, F.A.D.; Veras, C.A.G. Numerical simulation of oxy-fuel combustion for gas turbine. Appl. Therm. Eng. 2015, 78, 471-481. [CrossRef]

2. Anderson, S.; Newell, R. Prospects for Carbon Capture and Storage Technologies. RFF DP 02-68. 2003, pp. 109-142. Available online: http:/ / www.rff.org (accessed on 1 January 2004).

3. Gibbins, J.; Chalmers, H. Carbon capture and storage. Energy Policy 2008, 36, 4317-4322. [CrossRef]

4. Alfaro-Ayala, J.A.; Gallegos-Munoz, A.; Uribe-Ramirez, A.R.; Belman-Flores, J.M. Use of bioethanol in a gas turbine combustor. Appl. Therm. Eng. 2013, 61, 481-490. [CrossRef]

5. Sousa, J.; Paniagua, G.; Morata, E.C. Thermodynamic analysis of a gas turbine engine with a rotating detonation combustor. Appl. Energy 2017, 195, 247-256. [CrossRef]

6. Shah, R.D.; Banerjee, J. Thermal and emission characteristics of a CAN combustor. Heat Mass Transf. 2015, 52, 499-509. [CrossRef]

7. Chen, J.; Song, W.; Xu, D. Optimal combustor dimensions for the catalytic combustion of methane-air mixtures in micro-channels. Energy Convers. Manag. 2017, 134, 197-207. [CrossRef]

8. Tang, A.; Cai, T.; Deng, J.; Xu, Y.; Pan, J. Experimental investigation on combustion characteristics of premixed propane/air in a micro-planar heat recirculation combustor. Energy Convers. Manag. 2017, 152, 65-71. [CrossRef]

9. Kang, M.S.; Jeong, H.J.; Farid, M.M.; Hwang, J. Effect of staged combustion on low NOx emission from an industrial-scale fuel oil combustor in South Korea. Fuel 2017, 210, 282-289. [CrossRef]

10. Coriton, B.; Frank, J.H.; Gomez, A. Interaction of turbulent premised flames with combustion products: Role of stoichiometry. Combust. Flame 2016, 170, 37-52. [CrossRef]

11. Lourier, J.-M.; Stohr, M.; Noll, B.; Werner, S.; Fiolitakis, A. Scale adaptive simulation of a thermoacoustic instability in a partially premised lean swirl combustor. Combust. Flame 2017, 183, 343-357. [CrossRef]

12. Jiang, L.J.; Shy, S.; Nguyen, M.T.; Huang, S.Y.; Yu, D.W. Spark ignition probability and minimum ignition energy transition of the lean iso-octane/air mixture in premised turbulent combustion. Combust. Flame 2018, 187, 87-95. [CrossRef]

13. Zhou, H.; Li, S.; Ren, Z.; Rowinski, D.H. Investigation of mixing model performance in transported PDF calculations turbulent lean premixed jet flames through Lagrangian statistics and sensitivity analysis. Combust. Flame 2017, 181, 136-148. [CrossRef]

14. Lieuwen, T.; Torres, H.; Johnson, C.; Zinn, B.T. A mechanism of combustion instability in lean premixed gas turbine combustors. J. Eng. Gas Turbines Power 1999, 123, 182-189. [CrossRef] 
15. York, W.D.; Ziminsky, W.S.; Yilmaz, E. Development and testing of a low NOx hydrogen combustion system for heavy-duty gas turbines. J. Eng. Gas Turbines Power 2013, 135, 022001. [CrossRef]

16. Hamlington, P.E.; Darragh, R.; Briner, C.A.; Towery, C.A.Z.; Taylor, B.D.; Poludnenko, A.Y. Lagrangian analysis of high-speed turbulent premixed reacting flows: Thermochemical trajectories in hydrogen-air flames. Combust. Flame 2017, 186, 193-207. [CrossRef]

17. Zhang, Z.; Zhao, D.; Han, N.; Wang, S.; Li, J. Control of combustion instability with a tunable Helmholtz resonator. Aerosp. Sci. Technol. 2015, 41, 55-62. [CrossRef]

18. Ghani, A.; Poinsot, T.; Gicquel, L.; Staffelbach, G. LES of longitudinal and transverse self-excited combustion instabilities in a bluff-body stabilized turbulent premixed flame. Combust. Flame 2015, 162, 4075-4083. [CrossRef]

19. Anand, V.; George, A.S.; Driscoll, R.; Gutmark, E. Characterization of instabilities in a rotating detonation combustor. Int. J. Hydrogen Energy 2015, 40, 16649-16659. [CrossRef]

20. Hathout, J.P.; Fleifil, M.; Annaswamy, A.M.; Ghoniem, A.F. Combustion instability active control using periodic fuel injection. J. Propuls. Power 2002, 18, 390-399. [CrossRef]

21. Yuan, L.; Shen, C. Computational investigation on combustion instabilities in a rocket combustor. Acta Astronaut. 2016, 127, 634-643. [CrossRef]

22. Li, J.; Xia, Y.; Morgans, A.S.; Han, X. Numerical prediction of combustion instability limit cycle oscillations for a combustion with a long flame. Combust. Flame 2017, 185, 28-43. [CrossRef]

23. Keller, J.J. Thermoacoustic oscillations in combustion chambers of gas turbines. AIAA J. 1995, 33, $2280-2287$. [CrossRef]

24. Lieuwen, T.C. Experimental investigation of limit-cycle oscillations in an unstable gas turbine combustor. J. Propuls. Power 2002, 18, 61-67. [CrossRef]

25. Schuermans, B.; Guethe, F.; Pennell, D.; Guyot, D.; Paschereit, C.O. Thermoacoustic modeling of a gas turbine using transfer functions measured under full engine pressure. J. Eng. Gas Turbines Power 2010, 132, 111503-111511. [CrossRef]

26. Bellucci, V.; Schuermans, B.; Nowak, D.; Flohr, P.; Paschereit, C.O. Thermoacoustic modeling of a gas turbine combustor equipped with acoustic dampers. J. Turbomach. 2005, 127, 372-379. [CrossRef]

27. Akkerman, V.Y.; Law, C.K. Coupling of harmonic flow oscillations to combustion instability in premixed segments of triple flames. Combust. Flame 2016, 172, 342-348. [CrossRef]

28. O'Connor, J.; Hemchandra, S.; Lieuwen, T. Combustion instabilities in lean premixed systems. Technol. Control 2016, 2, 231-259.

29. Williams, F.A. Combustion Theory; Addison Wesley Publishing Company: Boston, MA, USA, 1985.

30. Fleilil, M.; Annaswamy, A.M.; Ghoneim, Z.A.; Ghoniem, A.F. Response of a laminar premixed flame to flow oscillations: A kinematic model and thermoacoustic instability results. Combust. Flame 1996, 106, 487-510. [CrossRef]

(C) 2018 by the authors. Licensee MDPI, Basel, Switzerland. This article is an open access article distributed under the terms and conditions of the Creative Commons Attribution (CC BY) license (http:/ / creativecommons.org/licenses/by/4.0/). 